\title{
SEZARY SYNDROME
}

(Report of Two Cases)

\section{CoI RAMJI RAI ${ }^{*}$, Maj (Mrs) R LAKHTAKIA ${ }^{+}$}

MJAFI 1998; 54 : 76-78

KEYWORDS : Sezary syndrome; Cutaneous T cell lymphomas.

\section{Introduction}

C utaneous $\mathrm{T}$ cell lymphomas (CTCL's) are a rare type of non Hodgkins lymphoma encompassing mycosis fungoides (MF) and its leukaemic counterpart Sezary syndrome (SS). Sezary syndrome was first described in 1938 and constitutes the triad of erythroderma, leukaemia with circulating mononuclear cells having convoluted nuclei (cerebriform lymphocytes) and lymph node enlargement due to infiltration by similar cells [1]. It is often referred to as 'the red man syndrome' or ' 1 ' homme rouge'. Clinically, this lesion is often misdiagnosed and treated as a chronic dermatitis or psoriasiform lesion. Failure to respond to treatment should prompt a search for a more serious disease in such cases. We present 2 cases of Sezary syndrome and discuss the diagnostic haematological features and recent advances in our understanding of this disease as well as the high index of suspicion in diagnosing this rare disease.

\section{Case Report}

Case 1

A 38-yeard-old male presented with 2 year history of a butterfly rash over the face and diffuse red scaly lesions over the trunk and extremities. The lesions were so intensely pruritic that he was bathing several times a day with cold water to relieve the burning. He was diagnosed prior to reporting to us as a case of discoid lupus erythematosus and was treated with steroid and antibiotic cream. On examination, he had multiple erythrodermic patches over the face and body. There was no splenomegaly and lymphadenopathy.

Investigations revealed $\mathrm{Hb} 13 \mathrm{gm}$ per cent TLC 22,000/cu.mm DLC P10 L90 per cent. Peripheral smear examination showed prominent lympocytosis. The lymphoid cells were large with moderate amount of cytoplasm and deep nuclear indentation and grooving (cerebriform cells). Bone marrow examination was normal. Transmission electron microscopy (TEM) of the buffy coat revealed typical Sezary cells with cerebriform nuclei. Nuclear grooves were deep and extended for more than half the diameter of the nucleus (Fig 1). Skin biopsy showed an upper dermal polymorphic lymphocytic infiltrate with bizarre mononuclear cells and epidermal Pautrier's microabscesses (Fig 2). A diagnosis of Sezary syndrome was made. The patient went to a cancer hospital in India and later abroad for treatment and died after 2 years.

Case 2

A 57-year-old male developed multiple, erythematous scaly lesions all over the body over a period of one year. Lesions were

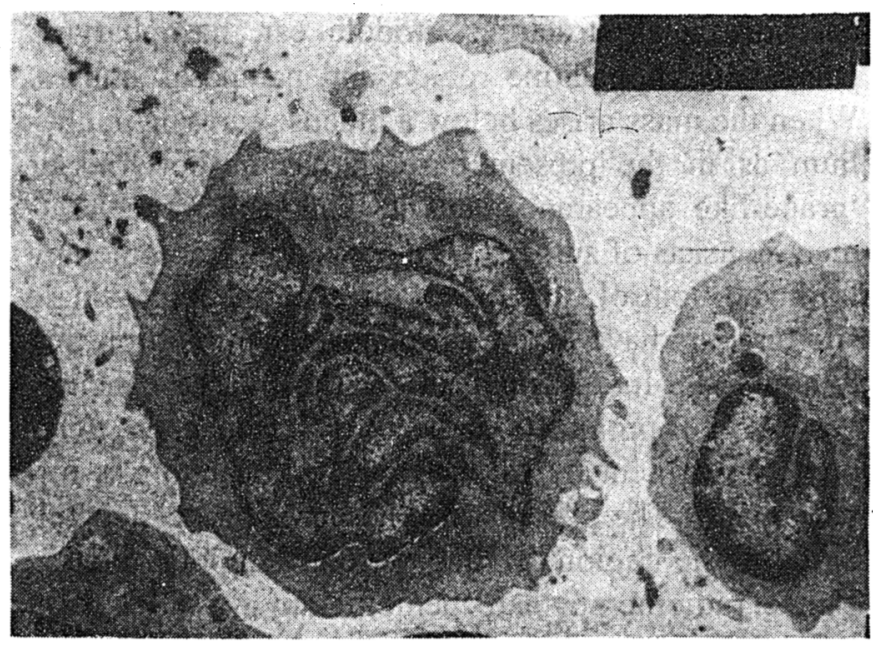

Fig. 1: Electron micrograph of Sezary cell from the buffy coat of Case 1 showing cerebriform nucleus with deep indentation (Uranyl acetate-lead citrate stain $\mathrm{x} 15,000$ )

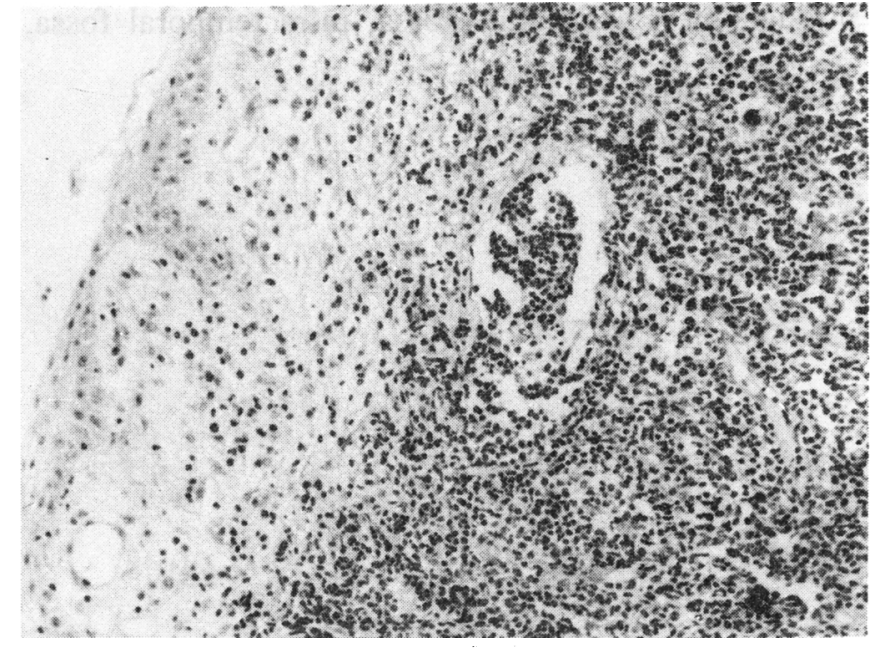

Fig. 2: A skin biopsy showing a polymorphic lymphocytic upper dermal infiltrate with evidence of epidermotropism (Haematoxylin and Eosin $x 10$ )

${ }^{*}$ Professor and Head, ${ }^{+}$Reader, Department of Pathology, Armed Forces Medical College, Pune 411040. 
itchy but there was no severe buring as in the first case. He was treated earlier as a case of psoriasis. Examination revealed splenomegaly but no lymphadenopathy.

\section{Investigations}

Hb 12 gm per cent TLC 33,000/cu.mm DLC P22L78. Abnormal lymphoid cells in the peripheral smear showed large deeply grooved 'cerebriform' nuclei. TEM confirmed the classical appearance of Sezary cells and skin biopsies showed a similar histological appearance as in Case 1. A diagnosis of Sezary syndrome was made. The patient died within 7 months of presenting to us.

\section{Discussion}

MF/SS comprise a small group of non Hodgkins lymphoma of $\mathrm{T}$ cell origin. MF presents primarily with skin lesions (erythroderma, plaque or nodules) while SS shows a leukaemic picture in addition to skin lesions. In SS clinically, the entire skin shows erythema, edema and lichenification. The erythrodermic lesions are intensely itchy, the intractable pruritis often resulting in excoriation and exudation. The 2 cases under study had erythroderma with no nodules or plaques, but had severe itching and burning.

The diagnosis of Sezary syndrome rests on the characteristic haematologic picture. There is, usually, a moderate leucocytosis ranging between 10,000 $30,000 / \mathrm{cu} . \mathrm{mm}$ with a marked lymphocytosis and sometimes eosinophilia. Though most patients with generalised erythroderma in mycosis fungoides have varying numbers of circulating Sezary cells [2], quantitative criteria for definitive diagnosis of Sezary syndrome have variably been quoted as $>15-20$ per cent cerebriform lymphocytes (especially the large cell variant) $[3,4],>1000 /$ uL CL's and $>5$ per cent convoluted CD4+ $T$ cells [5]. Sezary cells may be small $(8-11 \mathrm{u})$ or large $(12-14 \mathrm{u})$ and possess moderate amount of cytoplasm with nuclei showing indentation and grooving.

Electron microscopic features of Sezary cells were described initially by Lutzner in 1968, emphasizing the deeply indented nucleus with condensed chromatin [6]. Recently, more precise morphometry specifies that these cells have a nuclear contour index $\geq 7$ and a nuclear profile area $\geq 30 \mathrm{um}^{2}$ - this distinguishes $\mathrm{MF} / \mathrm{SS}$ from skin lesions of benign dermatoses. Epon embedded material stained with toluidine blue is said to give results comparable with EM [7]

Our cases showed evidence of leucocytosis with relative lymphocytosis and $>20$ per cent cerebriform cells in the peripheral blood. Electron microscopy confirmed the characteristic nuclear morphology of the cerebriform cells. Skin biopsy of the erythrodermic lesions showed cerebriform cells in a background of polymorphic inflammatory cells in the dermis and
Pautrier microabscesses in the overlying epidermis. Shaprio and Pinto emphasised the importance of recognising the neoplastic nature of $T$ cells in these lesions and the necessity of distinguishing them from mycosis-like cells in non-neoplastic lesions like acute or chronic dermatitis [8]. Thus, both clinically and on histology, a differential diagnosis of benign inflammatory dermatoses is entertained and treatment started with topical therapy till they are found to be unresponsive. This was seen in both our cases.

The neoplastic $\mathrm{T}$ cells are immunologically of helper CD4+ type and only occasionally CD8+ clones are identified [9]. Molecular diagnostic techniques have greately improved the recognition of neoplastic clones and early disease detection can now be done by studying $\mathrm{T}$ cell receptor genes in these cells [10].

Aetiologically, there is growing evidence of association of this disease with Human $\mathrm{T}$ cell lymphotropic viruses HTLV-I and HTLV-II [11] as well as HTLV-V. The epidermotropism in skin lesions has been explained by elaboration of interferon by the neoplastic $T$ cells which induces production of Intercellular adhesion moleculer-1 (ICAM-1) by keratinocytes. If this interaction is defective, neoplastic cells may preferentially move out to infiltrate blood; lymph node, viscera, etc [12].

Patients of MF/SS with limited plaque disease do well $(80 \%, 10$ year survival) while those with erythroderma have a poor prognosis $(25-35 \%, 10$ year survival). Treatment strategies involve the use of psoralen photochemotherapy, electron beam radiotherapy, systemic chemotherapy or combined modalities. Newer trials have used interferon and monoclonal antibodies.

In conclusion, these 2 cases of Sezary syndrome serve to highlight the dermatological features that are often confused with other diseases. Haematological and electron microscopic appearances diagnostic of this disease have been discussed and recent advances in our understanding of the pathologic mechanisms presented.

\section{REFERENCES}

1. Sezary A, Bouvrain Y. Erythrodermia avec presence de cellules mostreuses dans le derme et le sang circulant. Bull Soc Fr Dermatol Syphil 1938; 45: 254.

2. Kenneth AF, Fisher RI. Lymphomas. In: Bentler E, Lichtman MA, Coller BS, Kipps TJ, editors. William's Haematology. New York: McGraw Hill, 1995; 1088-90.

3. Vonderheid EC, Sobel EL, Nowel PC, et al. Diagnostic and prognostic significance of Sezary cells in peripheral blood smears from patients with cutaneous $\mathrm{T}$ cell lymphoma. Blood 1985; 66: 358-66. 
4. Willenze R, Van Wloten WA, Hermans J, Damsterg MJM, Meijer CJLM. Diagnostic criteria in Sezary syndrome: A multiparameter study of peripheral lymphocytes in $32 \mathrm{pa-}$ tients with erythroderma. J Invest Dermatol 1983; 81: 392-6.

5. Barcos M. Mycosis fungoides. Am J Clin Path 1993; 99: 452-63.

6. Lutzner MA, Jordan HW. The ultrastructure of an abnormal cell in Sezary's syndrome. Blood 1968; 31: 719-26.

7. Myrie C, Zucker-Franklin D, Ramsey D. Light microscopic analysis of sectioned Sezary cells: An accurate alternative to electron microscopy. Am J Pathol 1980; 99: 243-52.

8. Shapiro PE, Pinto JJ. The histologic spectrum of mycosis fungoides/Sezary syndrome (cutaneous $\mathrm{T}$ cell lymphoma) A review of 222 biopsies including newly described patterns and earliest pathologic changes. Am J Surg Pathol 1994; 18:
645-67.

9. Ralfkeir E. Immunohistological markers for the diagnosis of cutaneous lymphomas. Semin Diag Pathol 1991; 8: 62-71.

10. Weinberg JM, Rock AH, Lessin SR. Molecular diagnosis of lymphocytic infiltrates of the skin. Arch Dermatol 1993; 129 : 1491-500.

11. Zucker-Franklin D, Hooper WC, Evatt BL. Human lymphotropic retroviruses associated with mycosis fungoides. Evidence that human $T$ cell lymphotropic virus type II (HTLV-II) as well as HTLV-I may play a role in the disease. Blood 1992; 80: 1537-45.

12. Nickoloff BJ, Griffiths EM, Baadsgaard O, et al. Markedly diministed epidermal keratinocyte expression of intercellular adhesion molecule-I (ICAM-I) in Sezary syndrome. JAMA 1989; 261: 2217-21. 